\title{
Development of chromium and aluminum coatings on superalloys by pack-cementation technique
}

\author{
Xavier LEDOUX ${ }^{1, a}$, Michel VILASI ${ }^{1, b}$, Stéphane MATHIEU ${ }^{1, c}$, \\ Pierre-Jean PANTEIX ${ }^{1, \mathrm{~d}}$, Pascal DEL-GALLO ${ }^{2, \mathrm{e}}$ and Marc WAGNER ${ }^{2, \mathrm{f}}$ \\ ${ }^{1}$ Institute Jean Lamour - UMR 7198, CNRS Université Henri Poincaré Nancy 1, France \\ ${ }^{2}$ Research Center Claude-Delorme, Air Liquide, les Loges-en-Josas, France \\ axavier.ledoux@lcsm.uhp-nancy.fr, bmichel.vilasi@lcsm.uhp-nancy.fr, \\ 'stephane.mathieu@lcsm.uhp-nancy.fr, ${ }^{\mathrm{d}}$ pierre-jean.panteix@lcsm.uhp-nancy.fr, ${ }^{\mathrm{e}}$ pascal.del- \\ gallo@AirLiquide.com, 'marc.wagner@AirLiquide.com
}

Key words: coating, oxidation, high temperature, chromium, $\beta-\mathrm{NiAl}$

\begin{abstract}
Austenitic nickel-iron-chromium based superalloys are materials of choice for high temperature applications as they provide high temperature creep resistance associated with a suitable oxidation behavior in the temperature range of $600-1100^{\circ} \mathrm{C}$. However, these properties are not sufficient for applications as Steam Methane Reformer (SMR). As a consequence, aluminum and chromium coatings are developed by the pack-cementation technique to improve their corrosion resistance. The oxidation behavior of the coated samples has been carried out in air at $1050^{\circ} \mathrm{C}$. Chromium deposition leads to a layer of bcc chromium-iron solid solution. Oxidation tests indicated that a too high chromium concentration induces a too rapid growth of the chromia layer. In the case of aluminum coatings, a layer of $\beta$-NiAl is formed at the surface of the alloy. It permits a significant decrease of the oxidation rate.
\end{abstract}

\section{Introduction}

Iron - Nickel - Chromium alloys have been proven to be resistant to corrosive environments at high temperatures $\left(600-1000^{\circ} \mathrm{C}\right)$. Their good resistance is due to the chromium content (22 to $\left.28 \mathrm{wt} . \%\right)$ which allows the formation of a protective $\mathrm{Cr}_{2} \mathrm{O}_{3}$ layer [1].

For Steam Methane Reforming applications, operating conditions impose a carburizing atmosphere inside the reactor and an oxidizing one outside. In such conditions, Iron - Nickel - Chromium alloys do not permit a satisfactory life time of the reactor. This is the reason why it could be of interest to improve the resistance of these alloys by forming coatings on the surface.

Thus, the aim of our study is to develop chromium rich and aluminum rich coatings on Cr-rich austenitic alloys by a pack-cementation process and to carry out oxidation tests of the coated alloys in air at $1050^{\circ} \mathrm{C}$. Among the various techniques to form coatings, the pack cementation process is a very suitable technique as it permits the formation of homogeneous, adherent and thick coatings. Also, it is possible to deposit coatings on pieces of complex geometrical shapes. Chromium coatings should "play the role " of a chromium reservoir to avoid its fast depletion under the chromia layer while the aluminum coating should permit the formation of an $\mathrm{Al}_{2} \mathrm{O}_{3}$ layer which grows slower than the $\mathrm{Cr}_{2} \mathrm{O}_{3}$ layer [2].

The oxidation behavior of coated alloys was followed by TGA and samples were characterized by XRD, SEM and EPMA. In addition, the adhesion of the oxide scales has been evaluated by a cyclic oxidation test at $1000^{\circ} \mathrm{C}$ 


\section{Experimental procedures}

The substrate alloy employed throughout the present study consisted of a specific nickel-iron-base alloy with a principal $\mathrm{Cr}$ addition $(25 \%)$ and minor alloying elements: $\mathrm{Mo}, \mathrm{Co}, \mathrm{Mn}, \mathrm{W}, \mathrm{C}, \mathrm{N}$ and $\mathrm{Nb}$ (Table 1).

Table 1. Chemical composition of the alloy

\begin{tabular}{|c|c|c|c|c|}
\hline austenitic alloy & $\mathrm{Ni}$ & $\mathrm{Fe}$ & $\mathrm{Cr}$ & Other elements \\
\hline [wt. \%] & 37 & 33 & 25 & 5 \\
\hline
\end{tabular}

The samples were cut from a plate and their dimensions were approximately: $10 \mathrm{~mm}$ x $10 \mathrm{~mm} \times 0.5$ $\mathrm{mm}$. The surface preparation consisted of polishing until 800 grid and rounding the corner with SiC paper. Then, the samples were cleaned ultrasonically in ethanol.

In the case of chromium coatings, the pack mixture was composed of a $\mathrm{Cr}_{70} \mathrm{Fe}_{30}$ master alloy and $\mathrm{CrCl}_{3}$ (1 wt.\%). The chromization process was carried out by putting the mixture and sample in a quartz tube sealed under vacuum. The tube was then placed at 980 and $1100^{\circ} \mathrm{C}$ for 4,9 and 16 hours.

In the case of aluminum coatings, the pack was composed of a $\mathrm{Ni}_{2} \mathrm{Al}_{3}$ master alloy ( $\left.40 \mathrm{wt} . \%\right), \mathrm{CrCl}_{3}$ ( $1 \mathrm{wt} . \%)$ and $\mathrm{Al}_{2} \mathrm{O}_{3}$ as an inert filler $(60 \mathrm{wt} . \%)$. The aluminization process was carried out by placing the mixture and the sample(s) in an alumina crucible. The crucible was then introduced into an oven under Ar flow at $950^{\circ} \mathrm{C}$ for 20 hours. Thermodynamic calculations were executed by the HSC software.

Isothermal high temperature oxidations were performed in dry air flow by using a thermogravimetric analyzer: SETARAM SETSYS. The exposure time was 24 hours and the dwell temperature was $1050^{\circ} \mathrm{C}$. The phases were identified by X-ray diffraction, using $\mathrm{K} \alpha(0.154 \mathrm{~nm})$ copper radiation, on a Philips X'PERT pro diffractometer. After the oxidation process, the samples were observed using a scanning electron microscope (SEM). The layers were protected during polishing by electrodepositions of nickel. Elementary analysis was performed by Electron Probe Microanalysis (EPMA) on a Cameca SX100.

\section{Experimental results and discussion}

Thermodynamics. Before performing the experiments, the thermodynamics of the processes were simulated. Indeed, compositions of the gas phase can be calculated using HSC software for the two types of cementation. Results gave the partial pressure change of each gaseous species versus temperature. The data indicate that chromium dichloride $\left(\mathrm{CrCl}_{2}\right)$ in the case of chromization and $\mathrm{AlCl}$ in the case of aluminization are the gas vectors in the respective gas phase. This calculation step confirms the feasibility of the deposition process and validates the experimental conditions.

Chromization. The chromium coatings were carried out for two temperatures: 980 and $1100^{\circ} \mathrm{C}$, and three different durations: 4, 9 and 16 hours, so as to obtain the depositing rate. The results of mass gain versus the time of cementation indicate that the rate increases with the temperature of treatment and that the cementation obeys a parabolic law with time.

The characterizations of coatings are shown in Fig.1. The SEM micrographs of the cross-section show a homogeneous single-phased layer with a coating thickness of $50 \mu \mathrm{m}$ for 16 hours of sample treatment at $1100^{\circ} \mathrm{C}$. The XRD analysis reveals that the phase is cubic-centered. In addition, the concentration profile exhibits high chromium content in the layer: between 50 and 60 at.\%, signifying that the coating consists of a solid solution of chromium and iron. 
(a)

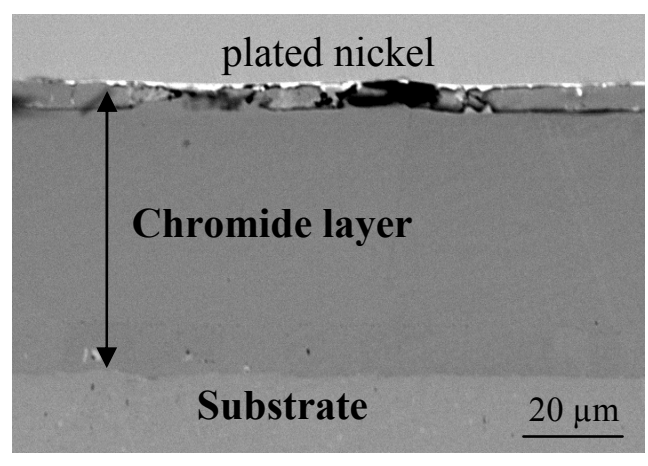

(b)

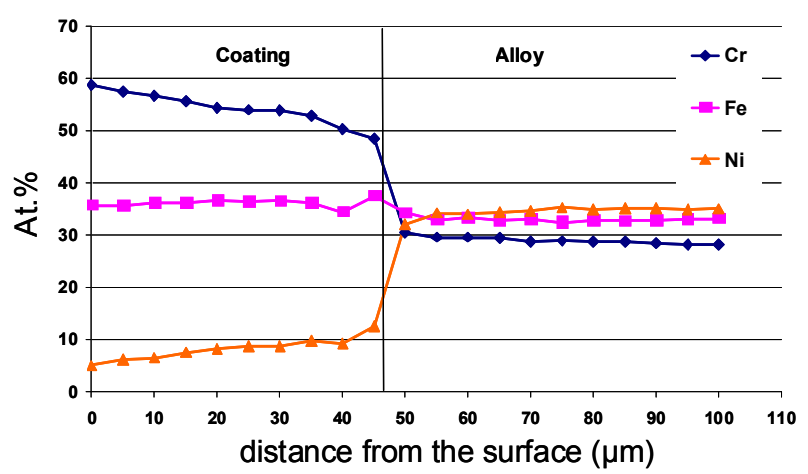

Fig. 1 (a) Cross-section of the chromization coating after $16 \mathrm{~h}$ of treatment at $1100^{\circ} \mathrm{C}$; (b) Concentration profile of the chromization coating

Aluminization. The aluminum coatings were performed at $950^{\circ} \mathrm{C}$ and for 20 hours. The characterizations of the coating are shown in Fig. 2. The cross-section micrograph shows a layer of around $35 \mu \mathrm{m}$ of thickness and an interdiffusion underlayer of $20 \mu \mathrm{m}$ of thickness. The XRD analysis shows that the phase of the coating is NiAl. The concentration profile points out that the ratio of aluminum in the layer is 50 at.\%. Nickel, iron and chromium are also present in varying ratios indicating that the scale is formed by NiAl with substitutions of nickel by iron and chromium. The underlayer is mainly composed of chromium and iron. Accordingly, the concentration gradient of nickel indicates the significant diffusion of this element into the coating during the treatment.

(a)

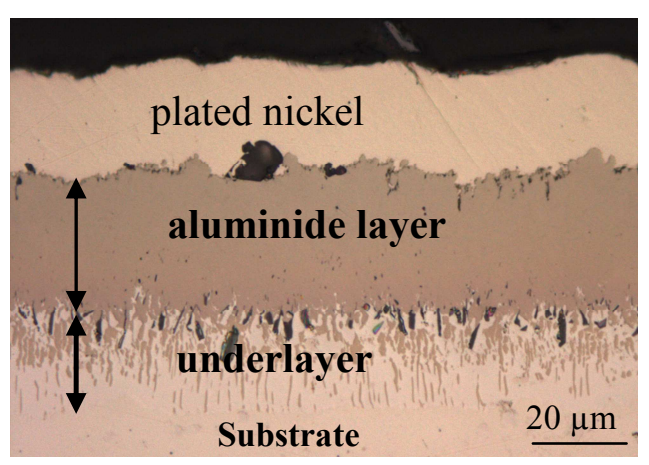

(b)

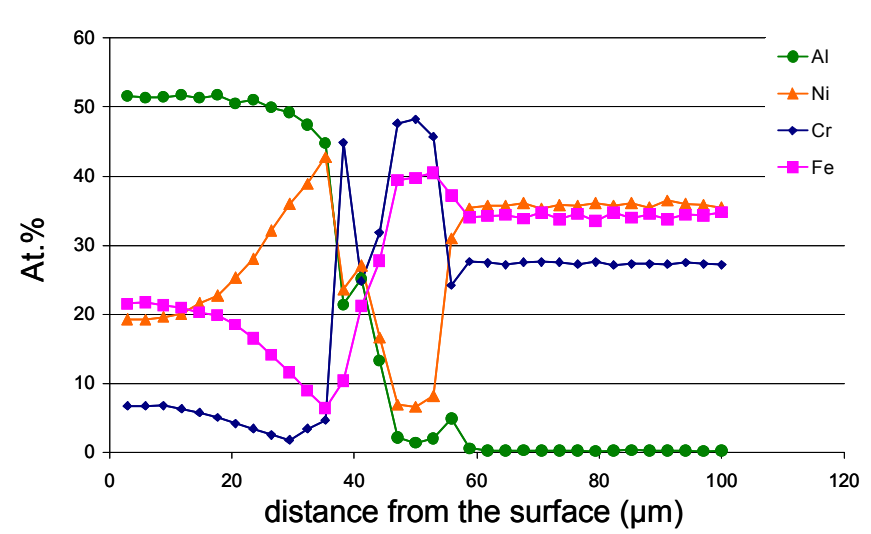

Fig. 1 (a) Cross-section of the aluminization coating after $20 \mathrm{~h}$ of treatment at $950^{\circ} \mathrm{C}$;

(b) Concentration profile of the aluminization coating

Oxidation kinetics. The oxidation kinetics of the aluminized and chromized alloys have been studied by TGA at $1050^{\circ} \mathrm{C}$ and compared to the uncoated alloy. The results are presented in Fig. 3 . The mass gain versus time of the samples shows that, after a transition time of about 1 hour, the oxidation reactions obey a parabolic law in all cases. The mass gain of the aluminized alloy is lower than that of the uncoated one. In the case of the chromized alloy, the mass gain is higher. The XRD spectra of the oxidized samples indicate that the oxide which develops on the chromium coating is $\mathrm{Cr}_{2} \mathrm{O}_{3}$, on the aluminum coating is $\alpha-\mathrm{Al}_{2} \mathrm{O}_{3}$ and a mixture of $\mathrm{NiCr}_{2} \mathrm{O}_{4}$ and $\mathrm{Cr}_{2} \mathrm{O}_{3}$ develops on the uncoated sample. 


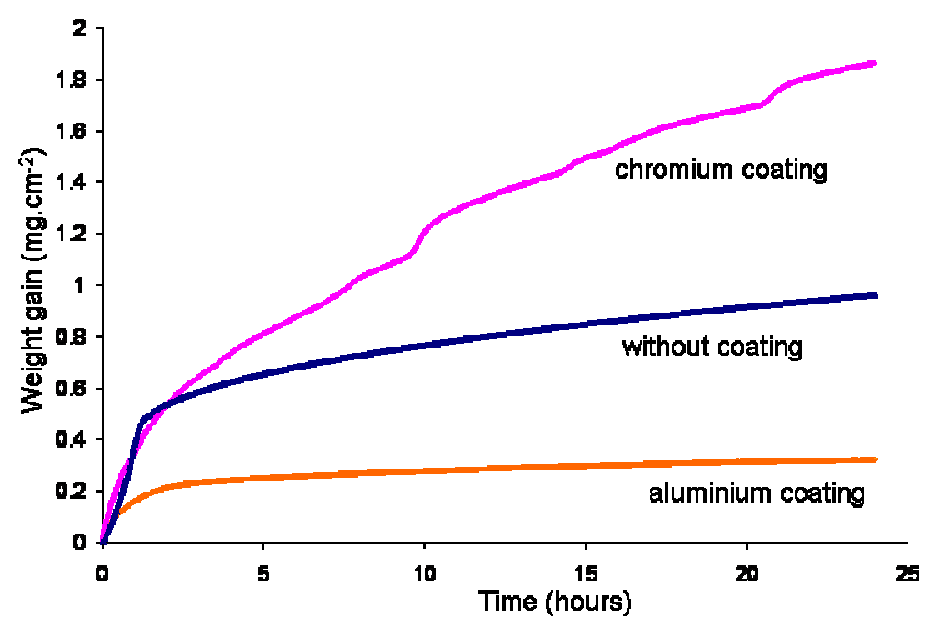

Fig. 3 weight gain versus time recorded in air at $1050^{\circ} \mathrm{C}$ for 24 hours.

The cross-section pictures of the samples after oxidation tests at $1050^{\circ} \mathrm{C}$ are shown in Fig. 4 .

(a)

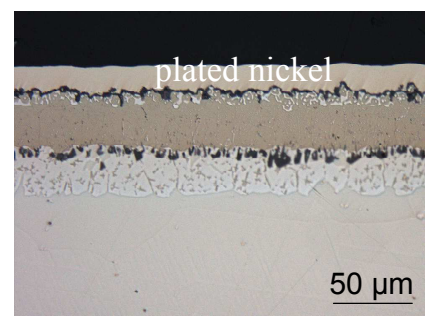

(b)

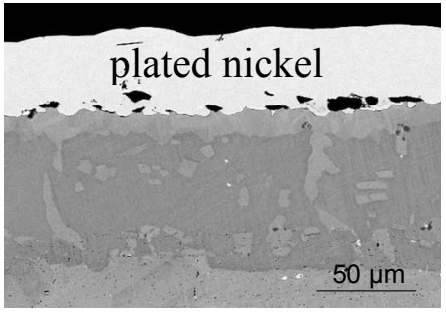

(c)

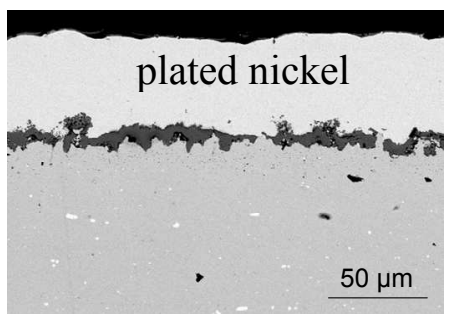

Fig. 4 Cross-sections of the (a) aluminized alloy, (b) chromized alloy and (c) uncoated alloy after oxidation for 24 hours in air at $1050^{\circ} \mathrm{C}$

Fig 4(a) shows that a thin $\mathrm{Al}_{2} \mathrm{O}_{3}$ layer of around $2 \mu \mathrm{m}$ thickness was formed at the surface of the aluminized sample during the oxidation. The structure of the aluminum coating did not change much after oxidation. However, at the surface, the aluminum depletion induces a modification of the NiAl phase into a new phase which was identified by XRD as being $\sigma-(\mathrm{Fe}, \mathrm{Cr})$. For the chromized sample, a spallation of the $\mathrm{Cr}_{2} \mathrm{O}_{3}$ layer is observed after the cooling step. Compared to the coated alloys, the uncoated one shows an oxide which is more adherent than that of the chromized sample but thicker than the alumina layer (between 5 and $10 \mu \mathrm{m}$ in average). These results are in accordance with Hindam and Whittle [2] as the value of the parabolic kinetic constant is lower for the $\mathrm{Al}_{2} \mathrm{O}_{3}$ formation than that of $\mathrm{Cr}_{2} \mathrm{O}_{3}$. However, the chromium is not efficient to play the role of a reservoir because the high proportion of chromium may induce a rapid growth of the oxide layer in accordance with Kofstad [3]. This process leads to stresses which cause cracks of the chromia and the partial re-oxidations of the coating [4]. This phenomenon is visible on the kinetic curves which present a succession of normal growth and breakdown of the oxide layer.

The oxidation cycle consisted of 1 hour of heating followed by 10 minutes of cooling.

The curves of cyclic oxidation versus time at $1000^{\circ} \mathrm{C}$ of the aluminized and uncoated alloys are presented in Fig. 5. This test indicates the high adhesion of the alumina scale compared to the chromia scale and the ability of the aluminum coating to preserve the alumina scale even after 3200 hours of cycles. 


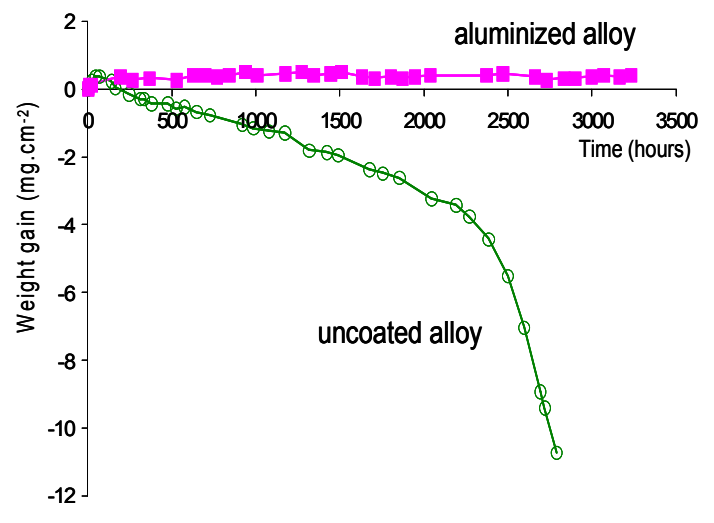

Fig. 5 Curves of the cyclic oxidation at $1000^{\circ} \mathrm{C}$ of the aluminized alloy and the uncoated alloy. The cycle is 1 hour of heating and 10 minutes of fast cooling in the laboratory air.

Alumina growth. Particular attention was given to the development of the alumina scale. It is well known that transient alumina can form on $\mathrm{NiAl}$ coatings [5,6,7]. Indeed, further experimentations at lower temperatures on the aluminized alloy exhibited two parabolic systems. The first one is transient and is observed during the beginning of the oxidation and the second one is steady and observed for long periods of oxidation. The parabolic kinetic constants were determined and presented in Fig. 6. According to the results of Grumm and Grabke [8] on the oxidation of NiAl, these results indicate that the growth of transient aluminas precedes the formation of the stable $\alpha$ $\mathrm{Al}_{2} \mathrm{O}_{3}$.

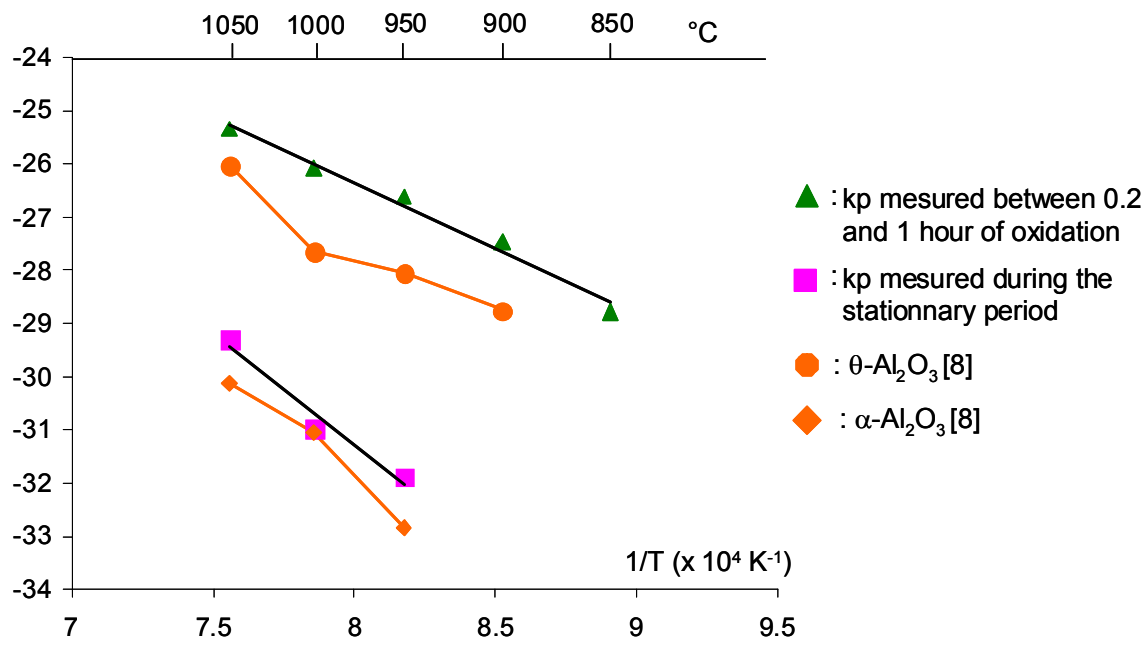

Fig. 6 Arrhenius plot of the parabolic kinetic constants, $\mathrm{k}_{\mathrm{p}}$ of aluminized alloy

The $k_{p}$ values measured before 1 hour of oxidation are a bit higher than those observed on pure $\mathrm{NiAl}$ [8]. Those measured at long periods of oxidation have almost the same values. In our case, substitution of nickel by iron and chromium seems to increase the growth rate of transient alumina but not that of the stable one.

XRD analyses identified the transient alumina as $\theta-\mathrm{Al}_{2} \mathrm{O}_{3}$ during 24 hours of oxidation in the range of $850-950^{\circ} \mathrm{C}$. At 1000 and $1050^{\circ} \mathrm{C}, \theta-\mathrm{Al}_{2} \mathrm{O}_{3}$ was not evidenced after the same period of oxidation. Activation energies that were calculated from the $\mathrm{k}_{\mathrm{p}}$ values are shown in Table 2. 
Table 2 Values of activation energies of alumina growth on both the aluminized alloy and pure $\mathrm{NiAl}$

\begin{tabular}{|c|c|c|}
\hline $\begin{array}{c}\text { Oxide } \\
\text { phase }\end{array}$ & $\begin{array}{c}\mathrm{Ea}\left[\mathrm{kJ} \cdot \mathrm{mol}^{-1}\right] \\
\text { of the aluminized alloy }\end{array}$ & $\begin{array}{c}\mathrm{Ea}\left[\mathrm{kJ} \cdot \mathrm{mol}^{-1}\right] \\
\text { of NiAl [8] }\end{array}$ \\
\hline$\theta-\mathrm{Al}_{2} \mathrm{O}_{3}$ & 205 & 231 \\
\hline$\alpha-\mathrm{Al}_{2} \mathrm{O}_{3}$ & 346 & 382 \\
\hline
\end{tabular}

The Ea values are a little lower than those found by Grumm and Grabke [8] on pure NiAl, indicating that chromium and iron facilitate the formation of the alumina scale.

It is noteworthy that the transient period before the growth of $\alpha-\mathrm{Al}_{2} \mathrm{O}_{3}$ is very short at 1000 and $1050^{\circ} \mathrm{C}$ : around one hour. This period increases when the temperature decreases: at $950^{\circ} \mathrm{C}$ it is around 65 hours while on pure NiAl it is around 250 hours [8]. So, these results confirm that the presence of chromium and iron probably catalyses the transition of $\theta-\mathrm{Al}_{2} \mathrm{O}_{3} / \alpha-\mathrm{Al}_{2} \mathrm{O}_{3}$ by the development of seeds of $\mathrm{Cr}_{2} \mathrm{O}_{3}$ and $\mathrm{Fe}_{2} \mathrm{O}_{3}$ at the beginning of the oxidation [9]. Indeed, these seeds may promote an epitaxial growth of $\alpha-\mathrm{Al}_{2} \mathrm{O}_{3}$.

\section{Conclusion}

Chromium and aluminum coatings were realized on a $\mathrm{Fe}-\mathrm{Ni}-\mathrm{Cr}$ alloy in agreement with the thermodynamic calculations. An $\alpha-\mathrm{FeCr}$ solid solution forms through chromium deposits whereas $\beta-(\mathrm{Ni}, \mathrm{Fe}, \mathrm{Cr}) \mathrm{Al}$ forms during aluminization. The alloy protected by the chromium rich coating exhibits a poor oxidation resistance due to too high amounts of chromium in the deposit, leading to a high strain level in the $\mathrm{Cr}_{2} \mathrm{O}_{3}$ layer.

The performances of $\mathrm{NiAl}$ coatings are validated by both cyclic and isothermal oxidation tests. The beneficial effect of $\mathrm{Cr}$ and $\mathrm{Fe}$ on the rate of the transition: transient alumina to stable $\alpha-\mathrm{Al}_{2} \mathrm{O}_{3}$ was observed.

\section{References}

[1] J.E. Croll and G.R. Wallwork, Oxid. Met., 4, 121 (1972)

[2] H. Hindam and D. P. Whittle, Oxid. Met., 18, 245 (1982)

[3] P. Kofstad, in "High temperature corrosion", Elsevier Applied Science (1988)

[4] L. Royer, X. Ledoux, S. Mathieu, P. Steinmetz, On the oxidation and nitridation of chromium at $1300^{\circ} \mathrm{C}$, Oxid. Met., in press 2010

[5] G. C. Rybicki and J. L. Smialek, Oxid. Met., 31, 275 (1989)

[6] B.A. Pint, I.G. Wright, W.Y. Lee, Y. Zhang, K. Prussner, K.B. Alexander Substrate and bond coat compositions: factors affecting alumina scale adhesion, Mat. Sci. and Eng. A. Vol. 245, 201-211 (1998)

[7] R.P. Blum, D. Ahlbehrendt, H. Niehus Growth of $\mathrm{Al}_{2} \mathrm{O}_{3}$ stipes on NiAl (001), Surf. Sci., Vol. 396 176-188 (1998)

[8] M. W. Brumm, H. J. Grabke, Corros. Sci., 33, 1677 (1992).

[9] P. Lamesle, M. Vilasi, J.M. Claude, P. Steinmetz Effect of Palladium and chromium additions on the oxidation behaviour of $\beta$-NiAl alloys, Les Embiez (1996). 